\title{
Nutritional management in hospital setting during SARS-CoV-2 pandemic: a real-life experience
}

\author{
Marco Cintoni $\mathbb{( I}^{1} \cdot$ Emanuele Rinninella $\mathbb{\circledR}^{2} \cdot$ Maria Giuseppina Annetta ${ }^{3} \cdot$ Maria Cristina Mele $^{4}$
}

Received: 13 March 2020 / Revised: 19 March 2020 / Accepted: 25 March 2020 / Published online: 6 April 2020

(c) Springer Nature Limited 2020

\section{To the Editor:}

Coronaviruses are a family of pathogens that primarily affect the human respiratory tract. In December 2019 first cases of a new Coronavirus (SARS-CoV-2) were reported in China [1]. On the 24th of March, the worldwide confirmed cases rose to 372.757 and 16.231 deaths, while in Italy, there were 63.927 total confirmed cases and 6.077 deaths [2]. On March 11, 2020, WHO declared the SARS-CoV-2 outbreak a pandemic [3].

While actual evidence is focusing on the general management of coronavirus disease (COVID-19), little is known regarding nutritional support during hospital stay (HS). The lack of nutritional procedures could, in turn, prolong patients' recovery and increase further infectious complications.

To better plan the nutritional management of this hospital emergency, we report the strategy adopted in our institution, the «Fondazione Policlinico A. Gemelli-IRCCS» of Rome, Italy, which recently became one of the COVID-19 reference centers in our region.

Marco Cintoni

marco.cintoni@gmail.com

1 Scuola di Specializzazione in Scienza dell'Alimentazione, Università di Roma Tor Vergata, Via Montpellier 1, 00133 Rome, Italy

2 UOC di Nutrizione Clinica, Dipartimento di Scienze Mediche e Chirurgiche, Fondazione Policlinico Universitario A. Gemelli IRCCS, Largo A. Gemelli 8, 00168 Rome, Italy

3 UOC di Anestesia, Rianimazione, Terapia Intensiva e Tossicologia Clinica, Dipartimento di Scienze dell'Emergenza, Anestesiologiche e della Rianimazione, Fondazione Policlinico Universitario A. Gemelli IRCCS, Largo A. Gemelli 8, 00168 Rome, Italy

4 UOSA di Nutrizione Avanzata in Oncologia, Dipartimento di Scienze Mediche e Chirurgiche, Fondazione Policlinico Universitario A. Gemelli IRCCS, Largo A. Gemelli 8, 00168 Rome, Italy
The two sides of the same coin are the following: nutritional support to the COVID-19 patients and meals supply to the healthcare professionals in wards (Fig. 1).

In planning nutritional support for the patients, the following conditions were considered:

- Since the median age of COVID-19 patients is 65 years old, their nutritional status may not be optimal.

- Fever and respiratory distress represent two factors that increase the energy expenditure.

- Isolation in small areas and bed resting induce a decrease in patients' muscle mass.

- During HS, a decrease in total energy and protein intake is frequently reported, due to the scarce palatability of hospital meals.

- Malnutrition is a frequent under-recognized and undertreated condition in hospital wards [4], and this aspect may worsen during a pandemic.

To meet the increased energy and protein requirements of the above-mentioned conditions, our institution started a personalized meal provision, combined with Oral Nutritional Supplements, to all oral-feedable COVID-19 patients, while those unable to eat are supported with high protein/low glucose Enteral and Parenteral Nutrition formulas, according to recent ESPEN guideline on clinical nutrition in the Intensive Care Unit [5].

Indeed, in the recent Chinese experience, nutritional support was considered a basic treatment and part of the multidisciplinary management for symptomatic SARS-CoV-2 affected patients [6, 7].

On the other side, the staff of the COVID-19 departments involved in the assistance, were provided with hot meals in disposable trays directly in the wards, with the addition of snacks and comfort food, since COVID-19 departments' shifts last $12 \mathrm{~h}$ and may result particularly heavy for personnel, deserving adequate nutritional support. This clinical choice has been made to avoid canteen meals, with a desirable reduction of SARS-CoV- 
Fig. 1 The nutritional management of COVID-19 units at Gemelli Hospital. Both patients and healthcare professionals are provided with personalized nutritional support.

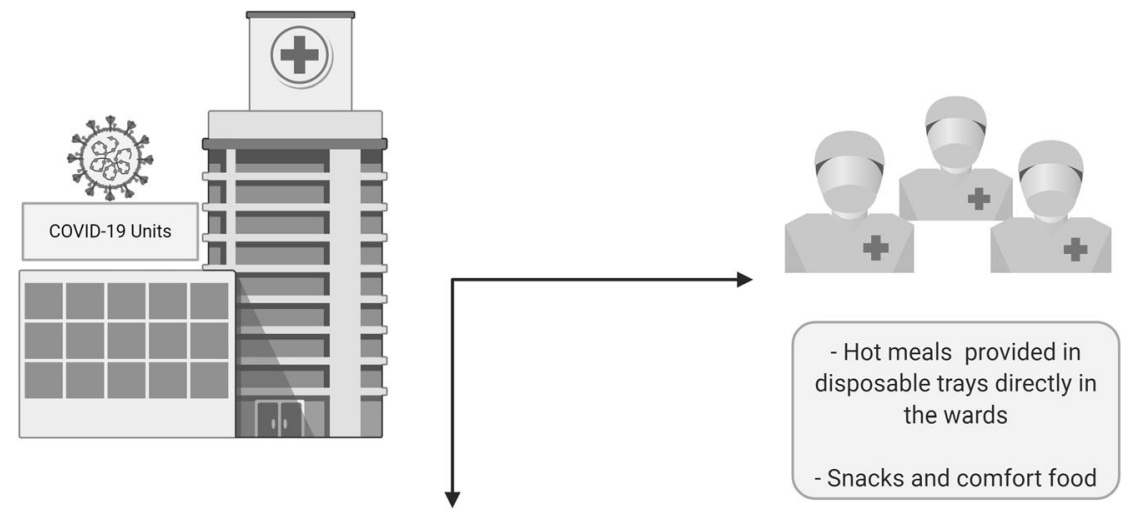

- Personalized meals

- Oral Nutritional Supplements (ONS)

- High Protein/ Low Glucose artificial nutrition (enteral/parenteral)

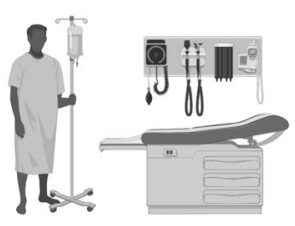

2 spread among healthcare staff and an effective saving of personal safety devices for our hospital.

Despite the absence of literature on nutritional support in a pandemic hospital setting, we want to advise all the clinical nutritionists to plan specific interventions in their hospital, directed both to avoid the potential spreading of SARS-CoV-2 through the canteen and to pay particular care to the nutritional status of the isolated and fragile COVID-19 patients.

\section{Compliance with ethical standards}

Conflict of interest The authors declare that they have no conflict of interest.

Publisher's note Springer Nature remains neutral with regard to jurisdictional claims in published maps and institutional affiliations.

\section{References}

1. Rothan HA, Byrareddy SN. The epidemiology and pathogenesis of coronavirus disease (COVID-19) outbreak. J Autoimmun.
2020; 102433. https://linkinghub.elsevier.com/retrieve/pii/S08968 41120300469 .

2. Situation Report-64 SITUATION IN NUMBERS total and new cases in last 24 h. 2020. https://www.who.int/docs/default-source/ coronaviruse/situation-reports/20200324-sitrep-64-covid-19.pdf? sfvrsn=703b2c40_2.

3. https://www.who.int/health-topics/coronavirus. Accessed 31 Mar 2020.

4. Rinninella E, Cintoni M, De Lorenzo A, Addolorato G, Vassallo G, Moroni R, et al. Risk, prevalence, and impact of hospital malnutrition in a Tertiary Care Referral University Hospital: a crosssectional study. Intern Emerg Med. 2018;13:689-97. https://doi. org/10.1007/s11739-018-1884-0.

5. Singer P, Blaser AR, Berger MM, Alhazzani W, Calder PC, Casaer MP, et al. ESPEN guideline on clinical nutrition in the intensive care unit. Clin Nutr 2019;38:48-79. https://doi.org/10.1016/j.clnu. 2018.08.037.

6. Chinese Medical Association. Specialty Branch Chinese Medical Association Parenteral Enteral Nutrition Branch Medical Nutrition Therapy Experts Recommendation. 2020. https://www.cma.org. cn/art/2020/1/30/art_15_32196.html.

7. Li XY, Du B, Wang YS, Kang HYJ, Wang F, Sun B, et al. [The keypoints in treatment of the critical coronavirus disease 2019 patient]. Zhonghua Jie He He Hu Xi Za Zhi. 2020;43:E026. https://doi.org/10.3760/cma.j.cn112147-20200224-00159. 